\title{
Obesity hypoventilation syndrome in Japan and independent determinants of arterial carbon dioxide levels.
}

\section{$\operatorname{AUTHOR}(\mathrm{S}):$}

Harada, Yuka; Chihara, Yuichi; Azuma, Masanori; Murase, Kimihiko; Toyama, Yoshiro; Yoshimura, Chikara; Oga, Toru; ... Mishima, Michiaki; Chin, Kazuo; Japan Respiratory Failure Group

\section{CITATION:}

Harada, Yuka ... [et al]. Obesity hypoventilation syndrome in Japan and independent determinants of arterial carbon dioxide levels.. Respirology 2014, 19(8): 1233-1240

\section{ISSUE DATE:}

2014-09-10

\section{URL:}

http://hdl.handle.net/2433/200266

\section{RIGHT:}

This is the peer reviewed version of the following article: Harada, Y., Chihara, Y., Azuma, M., Murase, K., Toyama, Y., Yoshimura, C., Oga, T., Nakamura, H., Mishima, M., Chin, K. and Japan Respiratory Failure Group (2014), Obesity hypoventilation syndrome in Japan and independent determinants of arterial carbon dioxide levels. Respirology, 19 1233-1240, which has been published in final form at http://dx.doi.org/10.1111/resp.12367. This article may be used for non-commercial purposes in accordance with Wiley Terms and Conditions for Self-Archiving: この論文は出版社版であ りません。引用の際には出版社版をご確認ご利用ください。; This is not the published version. Please cite only the published version. 


\section{Obesity hypoventilation syndrome in Japan and independent determinants of} arterial carbon dioxide levels

Yuka Harada, MD, ${ }^{1}$ Yuichi Chihara, MD, PhD, ${ }^{1}$ Masanori Azuma, MD, ${ }^{1}$ Kimihiko Murase, MD, ${ }^{1}$ Yoshiro Toyama, MD, ${ }^{1}$ Chikara Yoshimura, MD, PhD,${ }^{2}$ Toru Oga, MD, $\mathrm{PhD},{ }^{2}$ Hiroshi Nakamura, MD, PhD, ${ }^{3}$ Michiaki Mishima, MD, $\mathrm{PhD},{ }^{1}$ Kazuo Chin, $\mathrm{MD}$, $\mathrm{PhD},{ }^{2}$ and Japan Respiratory Failure Group

${ }^{1}$ Department of Respiratory Medicine, Graduate School of Medicine, Kyoto University, Kyoto, Japan, ${ }^{2}$ Department of Respiratory Care and Sleep Control Medicine, Graduate School of Medicine, Kyoto University, Kyoto, Japan, ${ }^{3}$ Nakamura Clinic, Urasoe, Japan.

Correspondence: Kazuo Chin, MD, PhD, Professor of Respiratory Care and Sleep Control Medicine, Graduate School of Medicine, Kyoto University, 54 Kawahara-cho, Shogoin, Sakyo-ku, Kyoto-city, Kyoto, 606-8507, Japan. Tel: +81-75-751-3852, Fax: +81-75-751-3854. E-mail: chink@kuhp.kyoto-u.ac.jp

Statement indicating the role of each author: Conception and design of the study: Y.H., 
Y.C., C.Y., K.C. Acquisition of data: Y.H., Y.C., M.A., K.M., Y.T., C.Y., T.O., K.C.

Analysis and interpretation of data: Y.H., Y.C., M.A., K.M., Y.T., C.Y., T.O., H.N., M.M.,

K.C. Drafting the article: Y.H., Y.C., M.M., K.C. Final approval: Y.H., Y.C., M.A., K.M., Y.T., C.Y., T.O., H.N., M.M., K.C.

The words count for the abstract: 246 words.

The words count for the text: 2498 words

\section{SUMMARY AT A GLANCE}

We aimed to reveal the prevalence and characteristics of OHS in Japan at present. The prevalence of OHS in obese OSA was approximately the same as in Western patients despite the much lower BMI compared with Westerns. Moreover, DLco/VA, firstly reported in this study, was independently associated with $\mathrm{PaCO}_{2}$ levels. 


\section{ABSTRACT}

Background and objective: The prevalence of obesity hypoventilation syndrome (OHS) was said to be $9 \%$ in patients with obstructive sleep apnoea (OSA) in Japan. However, the definition of OSA in that previous study was not an apnoea-hypopnoea index (AHI) $\geq 5 / \mathrm{h}$ but $\geq 20 / \mathrm{h}$ while under continuous positive airway pressure (CPAP) treatment. Therefore, the prevalence of OHS in OSA has not been well known in Japan as well as in other Asian countries. Our study objectives were to investigate the characteristics of Asian patients with OHS.

Methods: Investigated were 981 participants consecutively hospitalized for suspected OSA. At least $90 \%$ of them were from urban areas, including 162 with obese OSA (body mass index $(\mathrm{BMI}) \geq 30 \mathrm{~kg} / \mathrm{m}^{2}$ and $\mathrm{AHI} \geq 5 / \mathrm{h}$ ).

Results: The prevalence of OHS (BMI $36.7 \pm 4.9 \mathrm{~kg} / \mathrm{m}^{2}$ ) in OSA and that in obese OSA were $2.3 \%$ and $12.3 \%$, respectively. Multiple regression analysis revealed that independent of age and BMI, arterial oxygen pressure (contribution rate $\left(\mathrm{R}^{2}\right)=7.7 \%$ ), $4 \%$ oxygen desaturation index $\left(\mathrm{R}^{2}=8.9 \%\right)$, carbon monoxide diffusing capacity/alveolar volume (DLco/VA) $\left(\mathrm{R}^{2}=8.3 \%\right)$, which was firstly reported in this study, and hemoglobin concentration $\left(\mathrm{R}^{2}=4.9 \%\right)$ as well as waist circumference $\left(\mathrm{R}^{2}=4.9 \%\right)$ were independently associated with arterial carbon dioxide pressure. With $12.3 \pm 4.6$ months of CPAP 
treatment, more than $60 \%$ of OHS patients no longer had hypercapnia.

Conclusions: The prevalence of OHS in OSA in Japan was not 9\% but 2.3\%. The mean BMI of patients with OHS in Japan was lower than that in Western countries (36.7 $\mathrm{kg} / \mathrm{m}^{2}$ vs. $44.0 \mathrm{~kg} / \mathrm{m}^{2}$ ).

Key words: diffusion capacity, hypercapnia, hypoventilation, obesity, sleep apnoea.

Sort title: Obesity hypoventilation and $\mathrm{PaCO}_{2}$ 


\section{A LIST OF ABBREVIATIONS}

A-aDO 2 , alveolar-arterial oxygen pressure difference

AHI, apnoea-hypopnoea index

BMI, body mass index

BNP, brain natriuretic peptide

COPD, chronic obstructive pulmonary disease

CPAP, continuous positive airway pressure

CRP, C-reactive protein

DLco, carbon monoxide diffusing capacity

ERV, expiratory residual volume

ESS, Epworth Sleepiness Scale

$\mathrm{FEV}_{1}$, forced expiratory volume in 1 second

FRC, functional residual capacity

FVC, forced vital capacity

Hb, hemoglobin

HbA1c, hemoglobin A1c

$\mathrm{HCO}_{3}{ }^{-}$, bicarbonate

HDL-Chol, high density lipoprotein cholesterol 
HOMA-R, homeostasis model assessment of insulin resistance

LDL-Chol, low density lipoprotein cholesterol

NA, not applied

ODI, oxygen desaturation index

OHS, obesity hypoventilation syndrome

OSA, obstructive sleep apnoea

$\mathrm{PaCO}_{2}$, arterial carbon dioxide pressure

$\mathrm{PaO}_{2}$, arterial oxygen pressure

$\mathrm{pH}$, potential hydrogen

$\mathrm{R}^{2}$, contribution rate

RBC, red blood cells

$\mathrm{RV}$, residual volume

SD, standard deviation

$\mathrm{SpO}_{2}$, arterial oxygen saturation

T-Chol, total cholesterol

TG, triglyceride

TST, total sleep time

VA, alveolar volume 
WBC, white blood cells 


\section{INTRODUCTION}

In accordance with the continuing increases in rates of obesity, the incidence of obesity hypoventilation syndrome (OHS) has also increased. OHS is defined as the combination of obesity (body mass index $(\mathrm{BMI}) \geq 30 \mathrm{~kg} / \mathrm{m}^{2}$ ) and chronic daytime hypercapnia (arterial carbon dioxide pressure $\left.\left(\mathrm{PaCO}_{2}\right) \geq 45 \mathrm{mmHg}\right){ }^{1,2}$ In addition, the definition of OHS in previous reports included hypoxemia (arterial oxygen pressure $\left(\mathrm{PaO}_{2}\right)<70$ mmHg). ${ }^{3,4}$ It was reported that the prevalence of OHS in patients with obese obstructive sleep apnoea (OSA) was $10-20 \%{ }^{4-6}$ and that $0.3-0.4 \%$ of the general population might have OHS. ${ }^{7,8}$ OHS is an entity distinct from OSA or simple obesity and is associated with greater morbidity and mortality than either. ${ }^{9}$ Because of cephalometric differences, OHS may occur at a lower BMI in Asians than in Western individuals, as does OSA. ${ }^{10-12}$ In Japan, Akashiba et al. ${ }^{10}$ reported using data from 7 hospitals showing that OSA with hypercapnia was present in 9\% of patients with OSA (apnoea-hypopnoea index (AHI) $\geq$ 20 /h) who were under continuous positive airway pressure (CPAP) treatment and in $32 \%$ of patients with obese OSA (AHI $\geq 20 / \mathrm{h}$ and BMI $\geq 30 \mathrm{~kg} / \mathrm{m}^{2}$ ) who were receiving CPAP treatment. Therefore, there have been no data about $\mathrm{OHS}$ (BMI $\geq 30$ $\mathrm{kg} / \mathrm{m}^{2}$ and $\mathrm{PaCO}_{2} \geq 45 \mathrm{mmHg}$ ) in a large number of Asians, which definition was based on that in Western countries. 
Despite several reports that examined the determinants of $\mathrm{PaCO}_{2}$, diffusion capacity from pulmonary function tests, the disturbance of which is one factor related to hypoxemia, was not measured in previous reports, although hypercapnia with hypoxemia is an important issue in patients with $\mathrm{OHS}^{4}$ because hypoxemia is uncommon in patients with simple OSA. ${ }^{4}$

We hypothesized that the prevalence of OHS in individuals with OSA in Japan was not as high as $9 \%$ as previously reported ${ }^{10}$, and that in addition to obesity, other factors were independently associated with $\mathrm{PaCO}_{2}$. We also hypothesized that diffusion capacity, which was not investigated in previous reports, may be an important factor in OHS because it is considered that patients with OHS have a greater degree of hypoxemia than those with simple obesity. ${ }^{9}$ 
METHODS (Details are in Online Supporting Information.)

\section{Participants}

Participants were consecutively hospitalized in Kyoto University Hospital from October 2008 to September 2012 for a detailed examination for suspected OSA (Fig. 1). Owing to snoring, witnessed apnoea, daytime sleepiness, obesity, etc. about $60 \%$ were self-referrals and $40 \%$ were secondary referrals. Our hospital is located in the $7^{\text {th }}$ largest urban city (Kyoto) in Japan and adjacent to the $3^{\text {rd }}$ (Osaka) and $6^{\text {th }}$ (Kobe) largest cities. From the address of the participants, at least $90 \%$ were from urban areas. We based the diagnosis of $\mathrm{OHS}$ on a $\mathrm{BMI} \geq 30 \mathrm{~kg} / \mathrm{m}^{2}$ and $\mathrm{PaCO}_{2} \geq 45 \mathrm{mmHg}$ and that of hypoxemic OHS on a $\mathrm{BMI} \geq 30 \mathrm{~kg} / \mathrm{m}^{2}, \mathrm{PaCO}_{2} \geq 45 \mathrm{mmHg}$, and $\mathrm{PaO}_{2}<70 \mathrm{mmHg}$.

The study protocol was approved by the Kyoto University Graduate School and Faculty of Medicine Ethics Committee (approved number: E566). Informed consent was obtained from all patients. This clinical trial was registered in UMIN (reference number: UMIN000001931).

\section{Polysomnography}

Diagnosis of OSA was confirmed by polysomnography (SomnoStar pro, Cardinal Health, Dublin, OH, USA) as previously reported. ${ }^{13}$ Apnoea was defined as the 
complete cessation of airflow for at least 10 seconds and hypopnoea as a decrease in airflow of $50 \%$ or more lasting for at least 10 seconds, accompanied by oxygen desaturation of $\geq 3 \%$ or an arousal. ${ }^{14}$ The $4 \%$ oxygen desaturation index (ODI) was determined by the frequency of desaturations of $\geq 4 \%$ per hour.

\section{Assessment of pulmonary function}

Pulmonary function tests were performed using a standard spirometer, according to the recommended method. ${ }^{15}$ The values for carbon monoxide diffusing capacity (DLco) adjusted for hemoglobin were calculated. ${ }^{16}$

\section{Laboratory analyses of blood}

Arterial blood for blood gas analysis was drawn under room air conditions just before polysomnography started at night with the participants in the supine position that was maintained for 20 minutes before arterial blood was drawn.

\section{Statistical analysis}

Baseline characteristics are expressed as mean values with standard deviation (SD) or numbers. Normality and homogeneity of variance assumptions were checked before 
further analyses. After normality testing, all the variables were treated as parametric. Unpaired t-tests and chi-square tests were used to compare the backgrounds of two groups. In addition, the analysis of a covariance model adjusted for waist circumference was used to compare two groups. Relationships between two sets of continuous data were analyzed by Pearson's correlation coefficient tests and those of dichotomous data were analyzed by Spearman rank correlation coefficient. $P$ values $<0.05$ were considered to be statistically significant. Multiple regression analyses, with a $P$ value $<$ 0.10 for entry into the models, were performed to identify variables that could be best associated with $\mathrm{PaCO}_{2}$. Statistical analyses were performed using Statview 5.0 (SAS Institute, Inc. Cary, NC, USA). 
RESULTS (Details are in Online Supporting Information.)

\section{Characteristics of participants}

Of the 1127 patients assessed for suspected OSA, 981 participants (673 males and 308 females) were entered into the study (Fig. 1). In the excluded groups, there were 2 non-obese sever chronic obstructive pulmonary disease (COPD) patients (Fig. 1).

Table 1 shows characteristics of the 981 participants. Among them, 880 (89.7\%) had OSA (AHI $\geq 5 / \mathrm{h}$ ). Ninety-two (10.5\%) OSA patients had hypercapnia. The prevalence of OHS (BMI $\geq 30 \mathrm{~kg} / \mathrm{m}^{2}$ and $\mathrm{PaCO}_{2} \geq 45 \mathrm{mmHg}$ ) among the study participants was 2.1\% (21/981), and that of OHS among participants with OSA was 2.3\% (20/880). More than $95 \%(20 / 21)$ of the OHS patients had OSA (AHI $\geq 5 / h)$.

\section{Comparison between OHS and non-OHS in obese OSA}

Table 2 shows the comparison between the 162 obese OSA (BMI $\geq 30 \mathrm{~kg} / \mathrm{m}^{2}$ and AHI $\geq$ 5 /h) with and without OHS. Of patients with obese OSA, 20 (12.3\%) had OHS.

\section{Prevalence of OHS regarding the degree of obesity}

The prevalence of OHS in the patients with a BMI $30-34.9 \mathrm{~kg} / \mathrm{m}^{2}$ was $6.8 \%$, and that with a BMI $\geq 35 \mathrm{~kg} / \mathrm{m}^{2}$ was $25.0 \%$ (Fig. 2). Only 6 (3.6\%) of 169 patients with a BMI $\geq$ 
$30 \mathrm{~kg} / \mathrm{m}^{2}$ had a BMI $\geq 40 \mathrm{~kg} / \mathrm{m}^{2}$. Based on the estimate by the Ministry of Health, Labor and Welfare in Japan, individuals (age $\geq 15$ y) with a BMI $\geq 30 \mathrm{~kg} / \mathrm{m}^{2}$ comprised $3.9 \%$ of the Japanese population. ${ }^{17}$ We estimated that about $0.48 \%$ of the population in Japan might have OHS. When we compared OHS patients with and without hypoxemia, DLco was significantly lower in the hypoxemic OHS patients $(79.7 \pm 19.0 \%)$ than in those without hypoxemia $(96.4 \pm 8.4 \%)(P=0.033)$ (Table S1).

Multiple regression analysis to identify independent determinants of $\mathrm{CO}_{2}$ accumulation in obese OSA

$\mathrm{PaCO}_{2}$ had significant and independent associations not only with waist circumference (contribution rate $\left.\left(\mathrm{R}^{2}\right)=4.9 \%\right)$ but also with $\mathrm{PaO}_{2}\left(\mathrm{R}^{2}=7.7 \%\right), 4 \% \mathrm{ODI}\left(\mathrm{R}^{2}=8.9 \%\right)$, DLco/ alveolar volume (VA) $\left(\mathrm{R}^{2}=8.3 \%\right)$ and hemoglobin $\left(\mathrm{R}^{2}=4.9 \%\right)$ (Table 3 and Fig. 3). Among those variables, strong co-linearity was not found (Table S3). When using AHI, instead of $4 \% \mathrm{ODI}, \mathrm{PaCO}_{2}$ had significant and independent associations with the same factors.

\section{Improvements in arterial blood gas after CPAP treatment}

Of the 20 OHS patients with OSA, 18 OHS patients were introduced to CPAP treatment. 
Three of the 18 patients chose to discontinue CPAP treatments and one patient refused to provide arterial blood samples for blood gas analyses after CPAP treatment. Finally, we assessed data on 14 OHS patients with OSA that were obtained before and after CPAP treatment (Fig. S1).

In the 14 patients, $\mathrm{PaCO}_{2}$ significantly improved after more than 6 months of CPAP treatment (treatment duration; $12.3 \pm 4.6 \mathrm{mo}$ ) (Table 4). In 12 of the 14 OHS patients (85.7\%), $\mathrm{PaCO}_{2}$ improved and more than $60 \%$ of those patients $(9 / 14)$ had $\mathrm{PaCO}_{2}<45$ mmHg. Differences between before and after CPAP treatment in 4\%ODI and those in $\mathrm{PaCO}_{2}$ were significantly correlated $(\mathrm{r}=0.69, \mathrm{P}=0.005)$ (Fig. 4A).

Objective data on adherence indicated that CPAP adherence among the 14 patients was $3.0 \mathrm{~h}$ /day. Differences between before and after CPAP treatment in $\mathrm{PaCO}_{2}$ and CPAP adherence estimated for the month when arterial blood was drawn were significantly correlated ( $\mathrm{r}=0.62, P=0.016$ ) (Fig. 4B). 


\section{DISCUSSIONS}

In our study, the prevalence of OHS in OSA $(\mathrm{AHI} \geq 5 / \mathrm{h})$ was not $9 \%{ }^{10}$ but $2.3 \%$, while Akashiba et al. used a different definition (AHI $\geq 20 / \mathrm{h}$ on CPAP treatment $)^{10}$. Also, the prevalence of OHS in obese OSA (12.3\%) was estimated to be the same as in the West, but the mean BMI in patients with OHS in our study $\left(36.7 \mathrm{~kg} / \mathrm{m}^{2}\right)$ was lower than that in Western countries $\left(44 \mathrm{~kg} / \mathrm{m}^{2}\right) .{ }^{5,18}$ Multiple regression analysis revealed that, in addition to waist circumference, DLco/VA and hemoglobin level, $\mathrm{PaO}_{2}$ while awake and 4\%ODI were independently associated with $\mathrm{PaCO}_{2}$.

It is said that the prevalence of OHS in patients with OSA in Japan was $9 \%{ }^{10}$ and several reviews quoted that percentage as the prevalence of OHS in OSA in an Asian country (Japan). In addition to the fact that the participants were not consecutively enrolled and the data were acquired 10 years ago, it is highly important to consider that the definition of OHS in OSA in that report was not BMI $\geq 30 \mathrm{~kg} / \mathrm{m}^{2}, \mathrm{AHI} \geq 5 / \mathrm{h}$ and $\mathrm{PaCO}_{2} \geq 45 \mathrm{mmHg}$, which is usually recognized as the definition of OHS in OSA, but AHI $\geq 20 / \mathrm{h}$ under CPAP treatment and $\mathrm{PaCO}_{2} \geq 45 \mathrm{mmHg}$. From our consecutive data from one hospital in Japan, the prevalence of OHS in OSA (AHI $\geq 5 / h$ ) was $2.3 \%$. Although the prevalence of OHS in individuals with OSA was lower than previously reported, ${ }^{5}$ that of OHS in obese OSA (BMI $\geq 30 \mathrm{~kg} / \mathrm{m}^{2}$ and $\mathrm{AHI} \geq 5 / \mathrm{h}$ ) was $12.3 \%$, 
which was close to the frequency cited in previous reports. ${ }^{5,6,18}$

It has been reported that individuals with a BMI $\geq 30 \mathrm{~kg} / \mathrm{m}^{2}$ comprised $3.9 \%$ of the Japanese population ${ }^{17}$ and $30.3 \%$ of the U.S.A population. ${ }^{19}$ Therefore, although the prevalence of OHS in patients with $\mathrm{BMI} \geq 30 \mathrm{~kg} / \mathrm{m}^{2}$ was the same as in Western populations, its prevalence among our study patients increased more steeply with elevations in BMI than among Western populations (Fig. 2). Our data suggested that OSA could easily develop into OHS in Asians as they become more obese, as OSA itself develops in Asians with a low BMI. ${ }^{11,12,20}$ Young et al. ${ }^{12}$ reported that the craniofacial and upper airway structure had an important role in OSA occurrence and might be particularly significant in Asians. These craniofacial and upper airway characteristics in Asians may result in a worse AHI or 4\%ODI at a relative lower BMI than in Western individuals. Thus, hypercapnia could be worse in Asian patients with a lower BMI as well as OSA could.

Kaw et al. found that severity of obesity, severity of OSA, and pulmonary restrictive impairment were risk factors for hypercapnia. ${ }^{7}$ Two previous reports from $\operatorname{Japan}^{21,22}$ showed that not obesity but OSA related to AHI, nocturnal desaturation and pulmonary impairment play major roles in the cause of hypercapnia as indicated by some of the parameters in this study. In this study, 10.5\% (92/880) of the OSA patients (BMI 26.2 
$\mathrm{kg} / \mathrm{m}^{2}$ ) had hypercapnia, while $13.7 \%$ (168/1227) of the OSA patients (BMI $28.6 \mathrm{~kg} / \mathrm{m}^{2}$ ) had hypercapnia in a previous study. ${ }^{22}$ Although the prevalence of hypercapnia in OSA patients differed between studies, the characteristics of the previous cohort ${ }^{22}$ were almost the same as this study. Since the mean BMI in the former cohort ${ }^{22}$ was slightly larger than in ours $\left(28.6 \mathrm{~kg} / \mathrm{m}^{2}\right.$ vs. $\left.26.2 \mathrm{~kg} / \mathrm{m}^{2}\right)$, the prevalence of hypercapnia in OSA patients was slightly higher than in ours $(13.7 \%$ vs. $10.5 \%)$. It may indicate that the severity of OSA might play a larger role in Japanese patients than in Western populations.

This is the first report to reveal that DLco/VA was a significant determinant of hypercapnia in OHS. Obese patients have a high cardiac output and elevated total and central blood volume, which increase central circulatory congestion and capillary blood volume and result in elevations in DLco/VA. ${ }^{23-25}$ In addition, the low lung volume in the patients with OHS which was reported previously ${ }^{9,26}$ also might induce high DLco/VA. However, it should be noted that DLco/VA might produce a large number of false negative results, particularly in those with a low lung volume. In addition, whether this is an epiphenomenon or represents a genuine aspect of pathophysiology is unclear and needs further investigation.

Elevated hemoglobin in the OHS patients might be due to severe sustained 
desaturation during sleep $\left(\mathrm{SpO}_{2}<90\right.$ (\% total sleep time)). Recent data showed that sustained hypoxia induced increases in hemoglobin through hypoxia inducible factor- $1 .{ }^{27}$ Further research on the relationship between secondary polycythemia and hypercapnia in OSA should be done in the future.

Our results also implied that abdominal obesity, as assessed by waist circumference, has an independent effect on hypoventilation as previously reported. ${ }^{28}$ Abdominal obesity with increased waist circumference effected a restrictive respiratory impairment, which was associated with a reduction in $\mathrm{PaO}_{2},{ }^{29,30}$ inducing daytime hypoxemia. ${ }^{31}$ Our results could be important because hypoxemia induced by hypercapnia might worsen the hypercapnia and vice versa.

In our study, 4\%ODI was independently associated with $\mathrm{PaCO}_{2}$ (Table 3). In addition, the degrees of improvement in the 4\%ODI with CPAP treatment were significantly associated with those in $\mathrm{PaCO}_{2}$ levels (Fig. 4A). These data indicate that OSA induced worse awake $\mathrm{PaCO}_{2}$ levels in patients with OSA.

In our study, obese OSA patients with OHS had a larger waist circumference, presenting a greater restrictive load, than those without OHS (Table 2) although there was no difference in neck circumference. In this study, OHS patients seemed to be more amenable to correction of $\mathrm{PaCO}_{2}$ levels by CPAP treatment, which might be due to a 
lesser restrictive load with a lower BMI compared to the higher BMI in Western patients with OHS, along with the correction of upper airway collapse.

Our study had some limitations. First, it came from a single center. Second, the number of patients with OHS was small, although the analysis included a large number of patients ( $\mathrm{n}=981)$. Therefore, the conclusions should be viewed with caution. Third, OSA can coexist with COPD and causes greater oxygen desaturation and potential pulmonary hypertension. Thus, the true prevalence of OHS may be underestimated by excluding patients with COPD. However, in this study, since there were only 2 severe COPD patients and they were not obese, the effects of COPD with hypercapnia on the results of this study were slight.

In conclusion, the prevalence of OHS in Japan seems to be the same as in the West, even though the degree of obesity is less. In our patients with OHS, both sleep apnoea and diurnal oxygenation were independently associated with $\mathrm{PaCO}_{2}$ in addition to increases in DLco/VA. In our study, contribution rates of $\mathrm{PaO}_{2}$ or $4 \% \mathrm{ODI}$ to the variations in $\mathrm{PaCO}_{2}$ were lower than in previous reports, which might be due to racial differences among participants. For this reason, further studies are needed to examine differences in the pathophysiology of OHS according to racial and ethnic groups. 


\section{ACKNOWLEDGMENTS}

Japan Respiratory Failure Group consists of Drs. Kazuo Chin, Michiaki Mishima,

Shigeru Sakurai, Makoto Sato, Koichiro Tatsumi, Tsuneto Akashiba, Keiji Kubo,

Hiroki Sakakibara, Hiroshi Kimura, Motoharu Ohi, and Tomomasa Tsuboi.

This work was supported by grants from the Japanese Ministry of Education, Culture, Sports, Science and Technology, and Respiratory Failure Research Group from the Ministry of Health, Labor and Welfare of Japan. The Department of Respiratory Care and Sleep Control Medicine is funded by endowments from Philips-Respironics, Teijin Pharma, and Fukuda Denshi to Kyoto University. 


\section{REFERENCES}

1 Olson AL, Zwillich C. The obesity hypoventilation syndrome. Am. J. Med. 2005; 118: 948-56.

2 Sleep-related breathing disorders in adults: recommendations for syndrome definition and measurement techniques in clinical research. The Report of an American Academy of Sleep Medicine Task Force. Sleep 1999; 22: 667-89.

3 Subramanian S, Strohl KP. A Management Guideline for Obesity-Hypoventilation Syndromes. Sleep Breath. 1999; 3: 131-8.

4 Mokhlesi B. Obesity hypoventilation syndrome: a state-of-the-art review. Respir. Care 2010; 55: 1347-62.

5 Mokhlesi B, Tulaimat A, Faibussowitsch I, Wang Y, Evans AT. Obesity hypoventilation syndrome: prevalence and predictors in patients with obstructive sleep apnea. Sleep Breath. 2007; 11: 117-24.

6 Laaban JP, Chailleux E. Daytime hypercapnia in adult patients with obstructive sleep apnea syndrome in France, before initiating nocturnal nasal continuous positive airway pressure therapy. Chest 2005; 127: 710-5.

7 Kaw R, Hernandez AV, Walker E, Aboussouan L, Mokhlesi B. Determinants of hypercapnia in obese patients with obstructive sleep apnea: a systematic review and metaanalysis of cohort studies. Chest 2009; 136: 787-96. 
8 Mokhlesi B, Saager L, Kaw R. Q: Should we routinely screen for hypercapnia in sleep apnea patients before elective noncardiac surgery? Cleve. Clin. J. Med. 2010; 77: $60-1$.

9 Piper AJ, Grunstein RR. Obesity hypoventilation syndrome: mechanisms and management. Am. J. Respir. Crit. Care Med. 2011; 183: 292-8.

10 Akashiba T, Akahoshi T, Kawahara S, Uematsu A, Katsura K, Sakurai S, Murata A, Sakakibara H, Chin K, Hida W, Nakamura H. Clinical characteristics of obesity-hypoventilation syndrome in Japan: a multi-center study. Intern. Med. 2006; 45: $1121-5$

11 Yu X, Fujimoto K, Urushibata K, Matsuzawa Y, Kubo K. Cephalometric analysis in obese and nonobese patients with obstructive sleep apnea syndrome. Chest 2003; 124: 212-8.

12 Young T, Skatrud J, Peppard PE. Risk factors for obstructive sleep apnea in adults. $J$. A. M. A. 2004; 291: 2013-6.

13 Aihara K, Oga T, Harada Y, Chihara Y, Handa T, Tanizawa K, Watanabe K, Hitomi T, Tsuboi T, Mishima M, Chin K. Analysis of anatomical and functional determinants of obstructive sleep apnea. Sleep Breath. 2012; 16: 473-81.

14 Iber C, Ancoli-Israel S, Chesson AL, Quan SF (eds.) The AASM Manual for the 
Scoring of Sleep and Associated Events: Rules, Terminology and Technical

Specifications. American Academy of Sleep Medicine, Westchester, IL, USA, 2007.

15 Miller MR, Hankinson J, Brusasco V, Burgos F, Casaburi R, Coates A, Crapo R, Enright P, van der Grinten CP, Gustafsson P, Jensen R, Johnson DC, MacIntyre N, McKay R, Navajas D, Pedersen OF, Pellegrino R, Viegi G, Wanger J; ATS/ERS Task Force. Standardisation of spirometry. Eur. Respir. J. 2005; 26: 319-38.

16 Cotes JE, Dabbs JM, Elwood PC, Hall AM, McDonald A, Saunders MJ. Iron-deficiency anaemia: its effect on transfer factor for the lung (diffusiong capacity) and ventilation and cardiac frequency during sub-maximal exercise. Clin. Sci. 1972; 42: 325-35.

17 Ministry of Health, Labor and Welfare, March 2013. Report of National Heal th and Nutrition Survey. 2011. http://www.mhlw.go.jp/bunya/kenkou/eiyou/dl/h2 3-houkoku.pdf. Accessed: 13 January 2014.

18 Trakada GP, Steiropoulos P, Nena E, Constandinidis TC, Bouros D. Prevalence and clinical characteristics of obesity hypoventilation syndrome among individuals reporting sleep-related breathing symptoms in northern Greece. Sleep Breath. 2010; 14: 381-6.

19 Slack T, Myers CA, Martin CK, Heymsfield SB. The geographic concentration of 
U.S adult obesity prevalence and associated social, economic, and environmental factors. Obesity 2013 doi: 10.1002/oby.20502.

20 Sutherland K, Lee RW, Cistulli PA. Obesity and craniofacial structure as risk factors for obstructive sleep apnoea: impact of ethnicity. Respirology 2012; 17: 213-22

21 Akashiba T, Kawahara S, Kosaka N, Ito D, Saito O, Majima T, Horie T. Determinants of chronic hypercapnia in Japanese men with obstructive sleep apnea syndrome. Chest 2002; 121: 415-21.

22 Kawata N, Tatsumi K, Terada J, Tada Y, Tanabe N, Takiguchi Y, Kuriyama T. Daytime hypercapnia in obstructive sleep apnea syndrome. Chest 2007; 132: 1832-8.

23 Hughes JM, Pride NB. Examination of the carbon monoxide diffusing capacity (DLCO) in relation to its KCO and VA components. Am. J. Respir. Crit. Care Med. 2012; 186: 132-9.

24 Oppenheimer BW, Berger KI, Rennert DA, Pierson RN, Norman RG, Rapoport DM, Kral JG, Goldring RM. Effect of circulatory congestion on the components of pulmonary diffusing capacity in morbid obesity. Obesity 2006; 14: 1172-80.

25 Saydain G, Beck KC, Decker PA, Cowl CT, Scanlon PD. Clinical significance of elevated diffusing capacity. Chest 2004; 125: 446-52.

26 Mokhlesi B, Kryger MH, Grunstein RR. Assessment and management of patients 
with obesity hypoventilation syndrome. Proc. Am. Thorac. Soc. 2008; 5: 218-25.

27 Ryan S, Taylor CT, McNicholas WT. Selective activation of inflammatory pathways by intermittent hypoxia in obstructive sleep apnea syndrome. Circulation 2005; 112: 2660-7.

28 Zavorsky GS, Hoffman SL. Pulmonary gas exchange in the morbidly obese. Obes. Rev. 2008; 9: 326-39.

29 Busetto L, Sergi G. Visceral fat and respiratory complications. Diabetes Obes. Metab. 2005; 7: 301-6.

30 Enzi G, Vianello A, Baggio MB. Respiratory disturbances in visceral obesity. In: Oomura Y, Tarui S, Inoue S, Shimazu T (eds.) Progress in Obesity Research 1990. John Libbey \& C, London, UK, 1990; 335-9.

31 Salome CM, King GG, Berend N. Physiology of obesity and effects on lung function. J. Appl. Physiol. 2010; 108: 206-11. 


\section{FIGURE LEGENDS}

Figure 1 Study flowchart

OSA, obstructive sleep apnoea.

Figure 2 Prevalence of OHS according to the degree of obesity

OHS, obesity hypoventilation syndrome; BMI, body mass index.

- : results from our study, $\circ$ : results from the report by Mokhlesi et $\mathrm{al}^{5}$, a : results from the report by Laaban et $\mathrm{al}^{6}$

Figure 3 Independent contribution rate of each component to $\mathrm{PaCO}_{2}$

$\mathrm{PaCO}_{2}$, arterial carbon dioxide pressure; $\mathrm{PaO}_{2}$, arterial oxygen pressure; ODI, oxygen desaturation index; DLco/VA, carbon monoxide diffusing capacity/alveolar volume; Hb, hemoglobin.

口: waist circumference, $: \mathrm{PaO}_{2}, \mathbb{Z}: 4 \% \mathrm{ODI}$, 囲: DLco/VA, : $: \mathrm{Hb}, \square$ : others

\section{Figure 4}

A Relationship between differences between before and after CPAP treatment in $\mathrm{PaCO}_{2}$ and those in $4 \% \mathrm{ODI}$

r means correlation coefficient.

CPAP, continuous positive airway pressure; $\mathrm{PaCO}_{2}$, arterial carbon dioxide pressure; ODI, oxygen desaturation index. 
B Relationship between differences between before and after CPAP treatment in $\mathrm{PaCO}_{2}$

and CPAP adherence

r means correlation coefficient.

CPAP, continuous positive airway pressure; $\mathrm{PaCO}_{2}$, arterial carbon dioxide pressure. 
Table 1 Characteristics of study participants

\begin{tabular}{|c|c|}
\hline & All participants \\
\hline Number $(n)$ & 981 \\
\hline Men : Women & $673: 308$ \\
\hline OHS : non-OHS & 21: 960 \\
\hline Age (years) & $59 \pm 15$ \\
\hline BMI $\left(\mathrm{kg} / \mathrm{m}^{2}\right)$ & $25.8 \pm 5.0$ \\
\hline Neck circumference (cm) & $38.4 \pm 4.3$ \\
\hline Waist circumference (cm) & $92.2 \pm 13.3$ \\
\hline Waist-hip ratio & $0.99 \pm 0.65$ \\
\hline Pack years of smoking & $18.6 \pm 28.7$ \\
\hline ESS score & $9.7 \pm 5.3$ \\
\hline \multicolumn{2}{|l|}{ Arterial blood gas } \\
\hline $\mathrm{pH}$ & $7.42 \pm 0.03$ \\
\hline $\mathrm{PaCO}_{2}(\mathrm{mmHg})$ & $40.7 \pm 3.8$ \\
\hline $\mathrm{PaO}_{2}(\mathrm{mmHg})$ & $83.4 \pm 10.9$ \\
\hline $\mathrm{HCO}_{3}^{-}(\mathrm{mEq} / \mathrm{l})$ & $25.8 \pm 1.9$ \\
\hline $\mathrm{A}-\mathrm{aDO}_{2}(\mathrm{mmHg})$ & $15.7 \pm 11.7$ \\
\hline \multicolumn{2}{|l|}{ Sleep data } \\
\hline $\begin{array}{l}\text { Severity of OSA } \\
\text { (non/mild/moderate/severe) }\end{array}$ & $101 / 179 / 277 / 424$ \\
\hline AHI (/h) & $30.0 \pm 21.5$ \\
\hline Arousal index (/h) & $19.2 \pm 12.3$ \\
\hline 4\% ODI (/h) & $21.7 \pm 21.9$ \\
\hline $\mathrm{SpO}_{2}<90(\% \mathrm{TST})$ & $11.7 \pm 19.9$ \\
\hline minimum $\mathrm{SpO}_{2}(\%)$ & $81.1 \pm 9.4$ \\
\hline mean $\mathrm{SpO}_{2}(\%)$ & $93.9 \pm 3.1$ \\
\hline \multicolumn{2}{|l|}{ Pulmonary function } \\
\hline FVC (\% predicted) & $106.8 \pm 18.1$ \\
\hline $\mathrm{FEV}_{1} / \mathrm{FVC}(\%)$ & $77.5 \pm 8.4$ \\
\hline ERV (\% predicted) & $94.7 \pm 47.6$ \\
\hline FRC (\% predicted) & $108.0 \pm 50.9$ \\
\hline RV (\% predicted) & $115.4 \pm 42.5$ \\
\hline DLco (\% predicted) & $80.9 \pm 18.2$ \\
\hline DLco/VA (\% predicted) & $94.9 \pm 19.4$ \\
\hline Venous blood data & \\
\hline
\end{tabular}




\begin{tabular}{lc}
\hline Glucose (mg/dl) & $104 \pm 29$ \\
HbA1c (\%) & $5.7 \pm 1.0$ \\
TG (mg/dl) & $133 \pm 94$ \\
T-Chol (mg/dl) & $190 \pm 39$ \\
LDL-Chol (mg/dl) & $110 \pm 47$ \\
HDL-Chol (mg/dl) & $51 \pm 14$ \\
\hline
\end{tabular}

Data are presented as mean \pm standard deviation (SD) or numbers. $\mathrm{SpO}_{2}<90$ (\%TST) means the percentage of the total sleep time with $\mathrm{SpO}_{2}<90 \%$.

OHS, obesity hypoventilation syndrome; BMI, body mass index; ESS, Epworth Sleepiness Scale; $\mathrm{pH}$, potential hydrogen; $\mathrm{PaCO}_{2}$, arterial carbon dioxide pressure; $\mathrm{PaO}_{2}$, arterial oxygen pressure; $\mathrm{HCO}_{3}{ }^{-}$, bicarbonate; $\mathrm{A}-\mathrm{aDO}_{2}$, alveolar-arterial oxygen pressure difference; OSA, obstructive sleep apnoea; AHI, apnoea-hypopnoea index; ODI, oxygen desaturation index; $\mathrm{SpO}_{2}$, arterial oxygen saturation; TST, total sleep time; FVC, forced vital capacity; FEV 1 , forced expiratory volume in 1 second; ERV, expiratory residual volume; FRC, functional residual capacity; RV, residual volume; DLco, carbon monoxide diffusing capacity; VA, alveolar volume; HbA1c, hemoglobin A1c; TG, triglyceride; T-Chol, total cholesterol; LDL-Chol, low density lipoprotein cholesterol; HDL-Chol, high density lipoprotein cholesterol. 
Table 2 Comparison of obese OSA patients with and without OHS

\begin{tabular}{|c|c|c|c|c|c|}
\hline & All patients & OHS & Non-OHS & $P$-value & $\dagger P$-value \\
\hline Number ( $n(\%))$ & 162 & $20(12.3 \%)$ & $142(87.7 \%)$ & & \\
\hline Men : Women & $103: 59$ & $11: 9$ & $92: 50$ & 0.46 & - \\
\hline Age (years) & $53 \pm 13$ & $50 \pm 12$ & $54 \pm 13$ & 0.22 & 0.60 \\
\hline BMI $\left(\mathrm{kg} / \mathrm{m}^{2}\right)$ & $34.1 \pm 4.1$ & $36.7 \pm 4.9$ & $33.7 \pm 3.8$ & 0.002 & - \\
\hline Neck circumference $(\mathrm{cm})$ & $42.5 \pm 3.9$ & $42.4 \pm 4.6$ & $42.6 \pm 3.8$ & 0.91 & - \\
\hline Waist circumference (cm) & $110.9 \pm 12.6$ & $117.8 \pm 13.1$ & $110.0 \pm 12.2$ & 0.010 & NA \\
\hline Waist-hip ratio & $1.1 \pm 1.6$ & $1.0 \pm 0.04$ & $1.2 \pm 1.71$ & 0.70 & - \\
\hline Pack years of smoking & $20.6 \pm 33.3$ & $10.9 \pm 22.0$ & $22.1 \pm 34.5$ & 0.16 & 0.89 \\
\hline ESS score & $10.4 \pm 5.6$ & $10.6 \pm 6.8$ & $10.3 \pm 5.4$ & 0.86 & 0.69 \\
\hline \multicolumn{6}{|l|}{ Arterial blood gas } \\
\hline $\mathrm{pH}$ & $7.42 \pm 0.03$ & $7.39 \pm 0.03$ & $7.42 \pm 0.03$ & $<0.001$ & 0.78 \\
\hline $\mathrm{PaCO}_{2}(\mathrm{mmHg})$ & $41.2 \pm 4.4$ & $49.0 \pm 5.5$ & $40.2 \pm 2.8$ & $<0.001$ & 0.014 \\
\hline $\mathrm{PaO}_{2}(\mathrm{mmHg})$ & $77.5 \pm 10.2$ & $72.6 \pm 11.4$ & $78.2 \pm 9.8$ & 0.021 & 0.77 \\
\hline $\mathrm{HCO}_{3}^{-}(\mathrm{mEq} / \mathrm{l})$ & $25.8 \pm 2.1$ & $28.6 \pm 2.4$ & $25.4 \pm 1.7$ & $<0.001$ & 0.12 \\
\hline $\mathrm{A}-\mathrm{aDO}{ }_{2}(\mathrm{mmHg})$ & $21.0 \pm 11.2$ & $15.9 \pm 10.2$ & $21.7 \pm 11.2$ & 0.029 & 0.52 \\
\hline \multicolumn{6}{|l|}{ Sleep data } \\
\hline $\begin{array}{l}\text { Severity of OSA } \\
\text { (mild/moderate/severe) }\end{array}$ & 24/36/102 & 0/7/13 & 24/29/89 & 0.12 & - \\
\hline $\mathrm{AHI}(/ \mathrm{h})$ & $44.4 \pm 28.0$ & $61.6 \pm 40.0$ & $42.0 \pm 25.1$ & 0.003 & 0.048 \\
\hline Arousal index (/h) & $23.5 \pm 17.6$ & $32.7 \pm 29.0$ & $22.2 \pm 15.1$ & 0.013 & 0.010 \\
\hline 4\% ODI (/h) & $34.7 \pm 28.6$ & $56.7 \pm 42.6$ & $31.6 \pm 24.8$ & $<0.001$ & 0.039 \\
\hline $\mathrm{SpO}_{2}<90(\% \mathrm{TST})$ & $23.5 \pm 28.2$ & $45.5 \pm 37.5$ & $20.4 \pm 25.4$ & $<0.001$ & 0.50 \\
\hline minimum $\mathrm{SpO}_{2}(\%)$ & $76.0 \pm 10.7$ & $66.5 \pm 13.8$ & $77.4 \pm 9.6$ & $<0.001$ & 0.39 \\
\hline mean $\mathrm{SpO}_{2}(\%)$ & $91.9 \pm 4.2$ & $88.1 \pm 7.1$ & $92.5 \pm 3.3$ & $<0.001$ & 0.16 \\
\hline \multicolumn{6}{|l|}{ Pulmonary function } \\
\hline FVC (\% predicted) & $101.8 \pm 18.2$ & $92.8 \pm 19.9$ & $103.0 \pm 17.7$ & 0.031 & 0.33 \\
\hline $\mathrm{FEV}_{1} / \mathrm{FVC}(\%)$ & $79.2 \pm 8.2$ & $80.0 \pm 7.1$ & $79.1 \pm 8.3$ & 0.66 & 0.32 \\
\hline ERV (\% predicted) & $60.7 \pm 35.3$ & $51.7 \pm 42.8$ & $61.9 \pm 34.2$ & 0.27 & 0.013 \\
\hline FRC (\% predicted) & $126.5 \pm 109.0$ & $175.1 \pm 121.9$ & $120.1 \pm 106.0$ & 0.057 & 0.11 \\
\hline RV (\% predicted) & $117.8 \pm 36.5$ & $116.8 \pm 25.1$ & $117.9 \pm 37.8$ & 0.90 & 0.75 \\
\hline DLco (\% predicted) & $85.8 \pm 16.4$ & $91.2 \pm 17.4$ & $85.1 \pm 16.2$ & 0.16 & 0.55 \\
\hline DLco* (\% predicted) & $85.8 \pm 15.2$ & $89.1 \pm 16.0$ & $85.4 \pm 15.2$ & 0.36 & 0.46 \\
\hline DLco/VA (\% predicted) & $104.1 \pm 19.6$ & $118.5 \pm 17.6$ & $102.2 \pm 19.1$ & 0.002 & 0.25 \\
\hline DLco/VA* (\% predicted) & $104.1 \pm 18.6$ & $115.9 \pm 16.1$ & $102.6 \pm 18.5$ & 0.007 & 0.19 \\
\hline
\end{tabular}




\begin{tabular}{lccccc}
\hline Venous blood data & & & & & \\
WBC $\left(\times 10^{3} / \mu \mathrm{l}\right)$ & $6.45 \pm 1.98$ & $6.67 \pm 2.56$ & $6.42 \pm 1.89$ & 0.61 & 0.55 \\
RBC $\left(\times 10^{6} / \mu \mathrm{l}\right)$ & $4.76 \pm 0.55$ & $4.93 \pm 0.54$ & $4.74 \pm 0.55$ & 0.16 & 0.46 \\
Hb $(\mathrm{g} / \mathrm{dl})$ & $14.3 \pm 2.0$ & $14.9 \pm 1.7$ & $14.2 \pm 2.1$ & 0.17 & 0.44 \\
Platelets $\left(\times 10^{3} / \mu \mathrm{l}\right)$ & $221 \pm 62$ & $197 \pm 35$ & $224 \pm 64$ & 0.059 & 0.62 \\
Glucose $(\mathrm{mg} / \mathrm{dl})$ & $115 \pm 38$ & $108 \pm 30$ & $116 \pm 40$ & 0.41 & 0.57 \\
HbA1c $(\%)$ & $6.1 \pm 1.3$ & $6.2 \pm 1.4$ & $6.1 \pm 1.3$ & 0.86 & 0.21 \\
Insulin $(\mu \mathrm{U} / \mathrm{ml})$ & $18.1 \pm 16.3$ & $15.3 \pm 9.2$ & $18.5 \pm 17.1$ & 0.45 & 0.98 \\
HOMA-R & $5.1 \pm 5.1$ & $4.0 \pm 2.2$ & $5.3 \pm 5.4$ & 0.33 & 0.92 \\
TG (mg/dl) & $171 \pm 137$ & $151 \pm 102$ & $174 \pm 141$ & 0.51 & 0.84 \\
T-Chol $(\mathrm{mg} / \mathrm{dl})$ & $197 \pm 42$ & $205 \pm 47$ & $196 \pm 42$ & 0.44 & 0.15 \\
LDL-Chol $(\mathrm{mg} / \mathrm{dl})$ & $117 \pm 32$ & $126 \pm 36$ & $116 \pm 31$ & 0.19 & 0.056 \\
HDL-Chol (mg/dl) & $48 \pm 11$ & $49 \pm 9$ & $48 \pm 12$ & 0.68 & 0.90 \\
BNP $(\mathrm{pg} / \mathrm{dl})$ & $29.0 \pm 54.8$ & $25.3 \pm 26.0$ & $29.5 \pm 57.7$ & 0.77 & 0.56 \\
CRP $(\mathrm{mg} / \mathrm{dl})$ & $0.25 \pm 0.30$ & $0.34 \pm 0.36$ & $0.23 \pm 0.29$ & 0.20 & 0.24 \\
Fibrinogen (mg/dl) & $293 \pm 72$ & $315 \pm 67$ & $290 \pm 72$ & 0.18 & 0.63 \\
\hline
\end{tabular}

Data are presented as mean \pm SD or numbers (percent). $\mathrm{SpO}_{2}<90$ (\%TST) means the percentage of the total sleep time with $\mathrm{SpO}_{2}<90 \%$. $†$ P-value means the values after adjustment for waist circumference by analysis of covariance. DLco* (\% predicted) and DLco/VA* (\% predicted) are values for DLco (\% predicted) and DLco/VA (\% predicted) adjusted for values for hemoglobin.

OSA, obstructive sleep apnoea; OHS, obesity hypoventilation syndrome; BMI, body mass index; NA, not applied; ESS, Epworth Sleepiness Scale; pH, potential hydrogen; $\mathrm{PaCO}_{2}$, arterial carbon dioxide pressure; $\mathrm{PaO}_{2}$, arterial oxygen pressure; $\mathrm{HCO}_{3}{ }^{-}$, bicarbonate; $\mathrm{A}-\mathrm{aDO}_{2}$, alveolar-arterial oxygen pressure difference; AHI, apnoea-hypopnoea index; ODI, oxygen desaturation index; $\mathrm{SpO}_{2}$, arterial oxygen 
saturation; TST, total sleep time; FVC, forced vital capacity; $\mathrm{FEV}_{1}$, forced expiratory volume in 1 second; ERV, expiratory residual volume; FRC, functional residual capacity; RV, residual volume; DLco, carbon monoxide diffusing capacity; VA, alveolar volume; WBC, white blood cells; RBC, red blood cells; Hb, hemoglobin; HbA1c, hemoglobin A1c; HOMA-R, homeostasis model assessment of insulin resistance; TG, triglyceride; T-Chol, total cholesterol; LDL-Chol, low density lipoprotein cholesterol; HDL-Chol, high density lipoprotein cholesterol; BNP, brain natriuretic peptide; CRP, C-reactive protein. 
Table 3 Stepwise multiple regression analysis to reveal independent associated factors with $\mathrm{PaCO}_{2}$

\begin{tabular}{lcccc}
\hline & $\beta$ & $\mathrm{r}$ & $P$-value & $\mathrm{R}^{2}(\%)$ \\
\hline Waist circumference (cm) & 0.19 & 0.25 & 0.010 & 4.9 \\
$\mathrm{PaO}_{2}$ (mmHg) & -0.25 & -0.31 & 0.001 & 7.7 \\
4\%ODI (/h) & 0.22 & 0.41 & 0.008 & 8.9 \\
$\mathrm{DLco} / \mathrm{VA}$ (\% predicted) & 0.24 & 0.35 & 0.002 & 8.3 \\
$\mathrm{Hb}(\mathrm{g} / \mathrm{dl})$ & 0.17 & 0.29 & 0.026 & 4.9 \\
\hline Cumulative $\mathrm{R}^{2}$ & & & & 34.6 \\
\hline
\end{tabular}

In the stepwise multiple regression analyses, age, $\mathrm{BMI}$, waist circumference, $\mathrm{PaO}_{2}$, 4\%ODI, $\mathrm{SpO}_{2}<90$ (\%TST), FVC (\% predicted), DLco/VA (\% predicted), WBC and $\mathrm{Hb}$ were used as variables. Then, age, $\mathrm{BMI}, \mathrm{SpO}_{2}<90$ (\%TST), FVC (\% predicted) and WBC were excluded because of insignificance.

$\beta$ means standard regression coefficient, $\mathrm{r}$ means correlation coefficient and $\mathrm{R}^{2}$ indicates the contribution rate. $\mathrm{SpO}_{2}<90$ (\%TST) means the percentage of the total sleep time with $\mathrm{SpO}_{2}<90 \%$.

$\mathrm{PaCO}_{2}$, arterial carbon dioxide pressure; $\mathrm{PaO}_{2}$, arterial oxygen pressure; ODI, oxygen desaturation index; DLco/VA, carbon monoxide diffusing capacity/alveolar volume; Hb, hemoglobin; BMI, body mass index; $\mathrm{SpO}_{2}$, arterial oxygen saturation; $\mathrm{TST}$, total sleep time; FVC, forced vital capacity; WBC, white blood cells. 
Table 4 Anthropometry, arterial blood gas and sleep data in OHS before and after CPAP treatment

\begin{tabular}{|c|c|c|c|}
\hline & $\begin{array}{l}\text { Before } \\
(n=14)\end{array}$ & $\begin{array}{c}\text { After } \\
(n=14)\end{array}$ & $P$-value \\
\hline BMI $\left(\mathrm{kg} / \mathrm{m}^{2}\right)$ & $37.0 \pm 5.6$ & $35.8 \pm 4.9$ & 0.12 \\
\hline $\mathrm{pH}$ & $7.39 \pm 0.03$ & $7.41 \pm 0.02$ & 0.039 \\
\hline $\mathrm{PaCO}_{2}(\mathrm{mmHg})$ & $49.5 \pm 6.3$ & $43.8 \pm 2.9$ & 0.010 \\
\hline $\mathrm{PaO}_{2}(\mathrm{mmHg})$ & $73.6 \pm 13.0$ & $77.8 \pm 9.0$ & 0.24 \\
\hline $\mathrm{HCO}_{3}^{-}(\mathrm{mEq} / \mathrm{l})$ & $28.9 \pm 2.7$ & $27.1 \pm 1.9$ & 0.021 \\
\hline $\mathrm{A}-\mathrm{aDO}_{2}(\mathrm{mmHg})$ & $14.2 \pm 11.5$ & $17.2 \pm 7.0$ & 0.36 \\
\hline $\mathrm{AHI}(/ \mathrm{h})$ & $66.1 \pm 42.9$ & $8.2 \pm 5.5$ & $<0.001$ \\
\hline 4\%ODI (/h) & $60.4 \pm 46.5$ & $4.4 \pm 3.2$ & $<0.001$ \\
\hline $\mathrm{SpO}_{2}<90(\% \mathrm{TST})$ & $50.2 \pm 42.6$ & $6.8 \pm 21.1$ & 0.001 \\
\hline
\end{tabular}

Data are presented as mean $\pm \mathrm{SD}$. $\mathrm{SpO}_{2}<90$ (\%TST) means the percentage of the total sleep time with $\mathrm{SpO}_{2}<90 \%$.

Values for AHI, 4\%ODI and $\mathrm{SpO}_{2}<90$ (\%TST) after CPAP treatment were obtained from data of a repeated polysomnography in a laboratory setting after 2 days of CPAP usage.

OHS, obesity hypoventilation syndrome; CPAP, continuous positive airway pressure; BMI, body mass index; $\mathrm{pH}$, potential hydrogen; $\mathrm{PaCO}_{2}$, arterial carbon dioxide pressure; $\mathrm{PaO}_{2}$, arterial oxygen pressure; $\mathrm{HCO}_{3}{ }^{-}$, bicarbonate; $\mathrm{A}-\mathrm{aDO}_{2}$, alveolar-arterial oxygen pressure difference; AHI, apnoea-hypopnoea index; ODI, oxygen desaturation index; $\mathrm{SpO}_{2}$, arterial oxygen saturation; TST, total sleep time. 


\section{Figure 1}

Participants assessed for suspected OSA from October 2008 to September 2012 $(n=1127)$

Excluded $(n=113)$

- previously diagnosed with OSA or treated for OSA $(n=96)$

- presence of other hypercapnic diseases $(n=17)$

Participants analyzed

$(n=981)$ 
Figure2

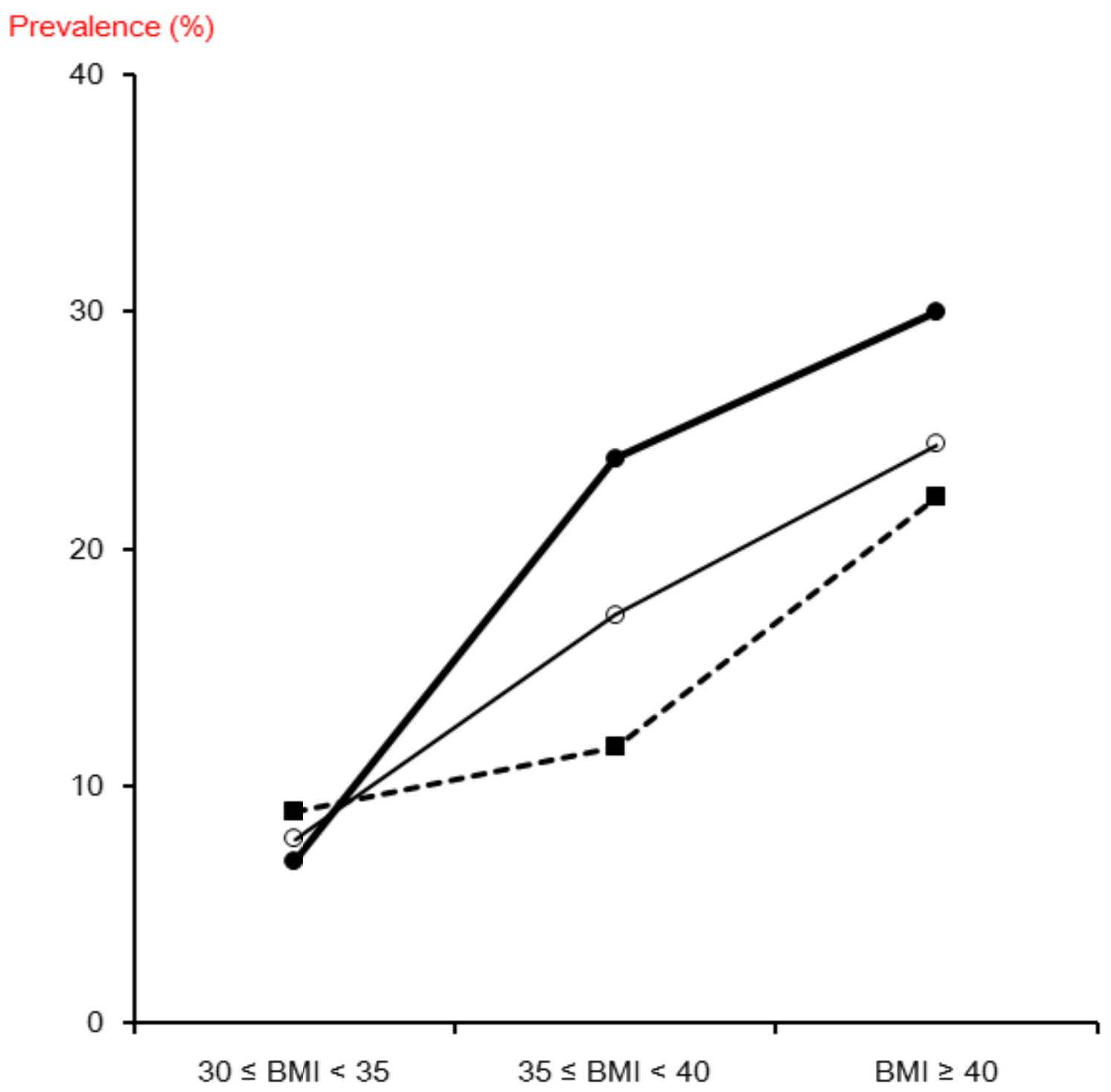

Our study

$\multimap$ Mokhlesi et $\mathrm{al}^{5}$

- - Laaban et al ${ }^{6}$ 
Figure 3

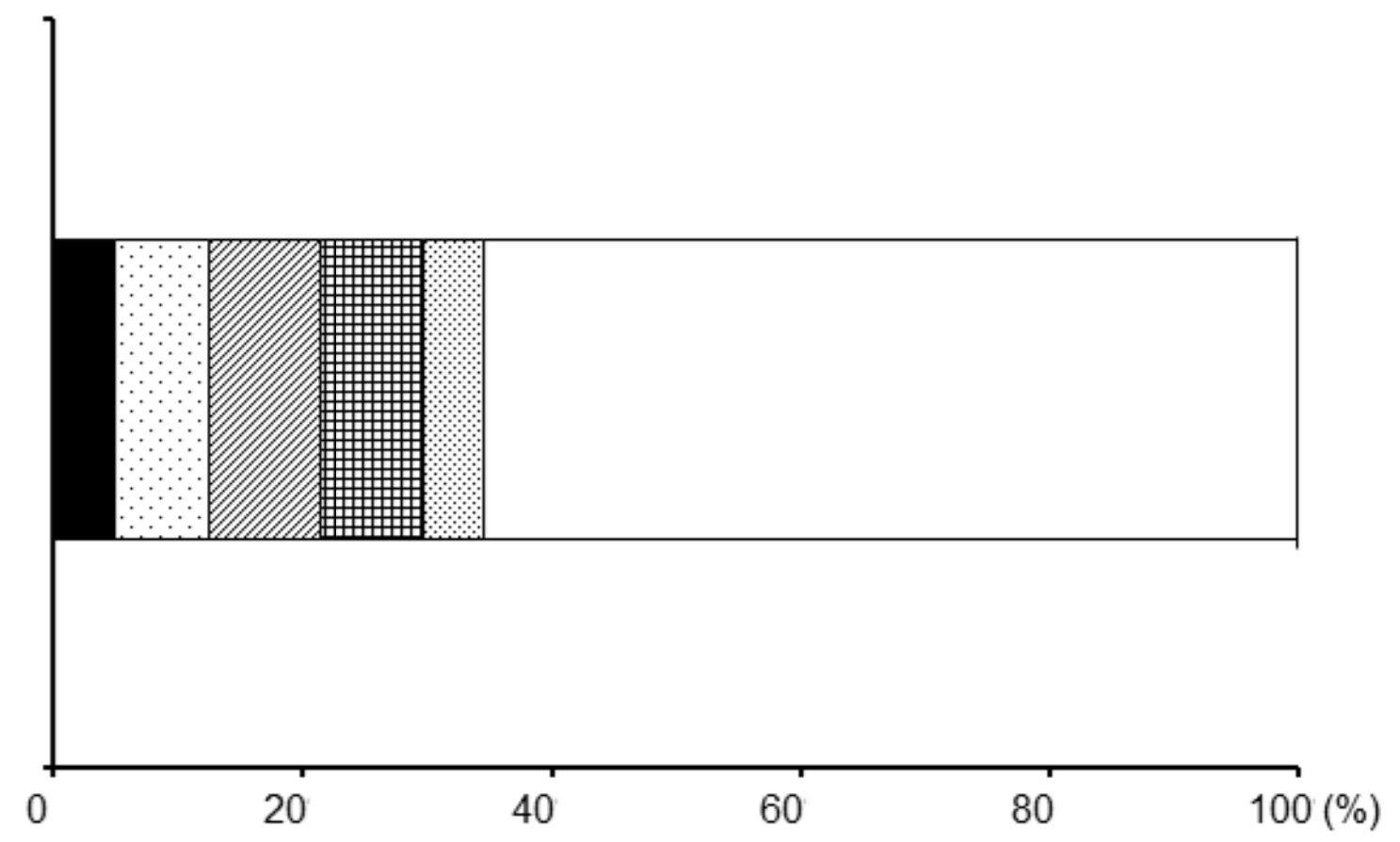

- Waist circumference

च $4 \% \mathrm{ODI}$

$\mathrm{Hb}$ $\square \mathrm{PaO}_{2}$

田DLco/VA

口others 


\section{Figure4}

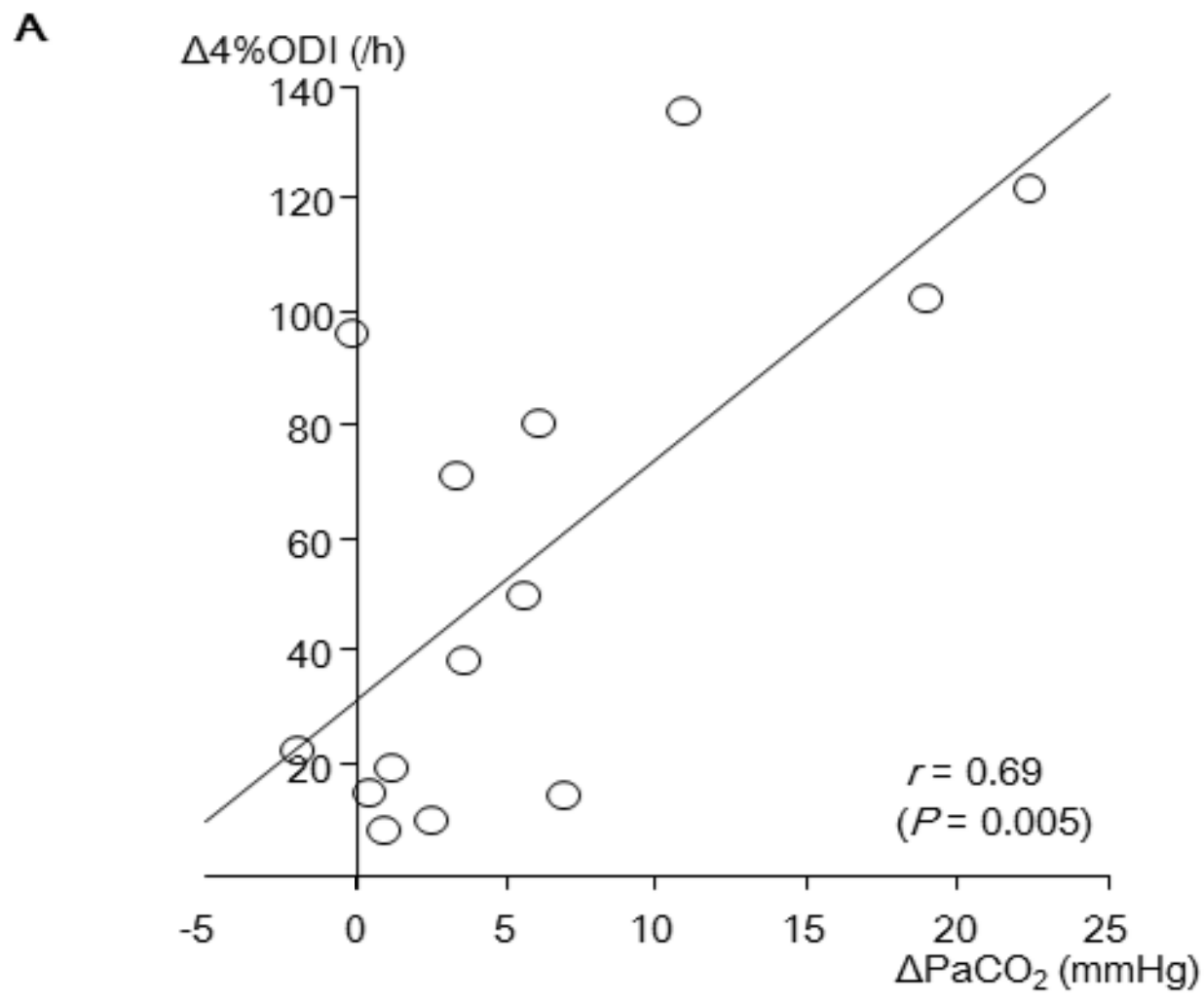

B

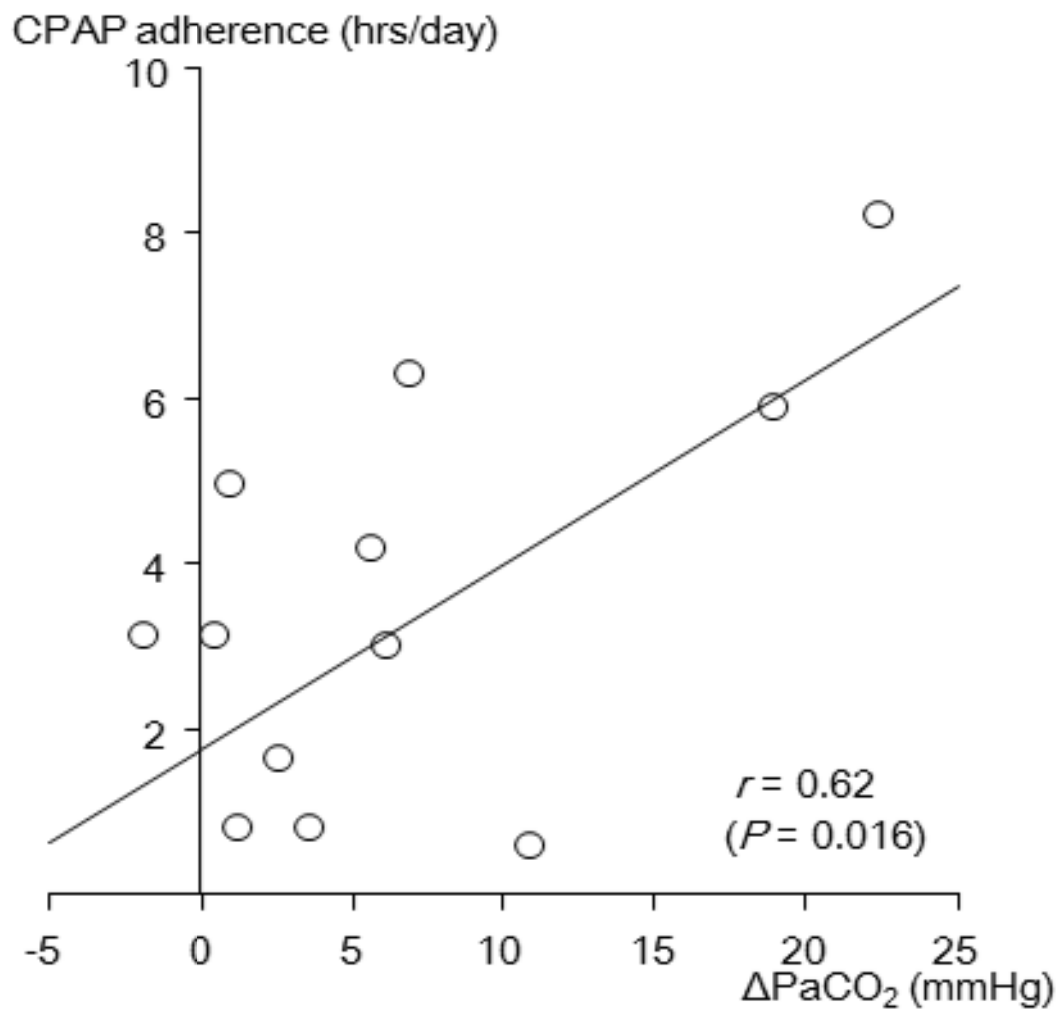

